\title{
Les premiers Hommes en Normandie
}

\section{Dominique Cliquet}

\section{OpenEdition \\ Journals}

Édition électronique

URL : http://journals.openedition.org/adlfi/7323

ISSN : 2114-0502

Éditeur

Ministère de la culture

Référence électronique

Dominique Cliquet, «Les premiers Hommes en Normandie », ADLFI. Archéologie de la France -

Informations [En ligne], Basse-Normandie, mis en ligne le 01 mars 2007, consulté le 02 mai 2019. URL http://journals.openedition.org/adlfi/7323

Ce document a été généré automatiquement le 2 mai 2019.

(c) Ministère de la Culture et de la Communication, CNRS 


\title{
Les premiers Hommes en Normandie
}

\author{
Dominique Cliquet
}

Date de l'opération : 2007 (PC)

Inventeur(s) : Cliquet Dominique (SRA)

Le projet collectif de recherche «Les Premiers Hommes en Normandie» a maintenant sept ans, en principe... « l'âge de raison ». Les nombreux travaux réalisés et ceux en cours sembleraient confirmer cette « maturité ». En effet, l'année 2007 a permis l'aboutissement et la «livraison » de deux importantes monographies, la première consacrée au site de boucherie de Ranville (Calvados), la seconde, aux occupations paléolithiques des Pléistocènes moyen et supérieur du site du Long-Buisson à Évreux (Eure).

Ces travaux apportent leur concours à la connaissance des modes de vie des Néandertaliens d'Europe occidentale dans un cadre environnemental et chronologique de plus en plus précis.

Parallèlement, l'activité de terrain a été plus importante cette année, tant au plan des opérations de fouilles que des prospections.

Enfin, comme l'an passé, parmi les points forts des activités conduites en 2007, figure la mise en place d'une cartographie vectorisée relative aux matières premières potentiellement utilisables par les pré- et protohistoriques (Anne Ropars, J.P. Coutard et Dominique Cliquet). Le travail sera poursuivi en 2008 et complété par la collecte de matières premières suivant un protocole bien établi, visant à la constitution d'une lithothèque, pour la Basse-Normandie.

Une nouvelle fois, les sondages programmés à Rânes ont dû être reportés en raison des intempéries (sol gorgé d'eau toute l'année).

Parmi les axes de recherches privilégiés figure depuis maintenant six ans la constitution d'un cadre chronologique fondé sur les méthodes physiques. Cette année encore, nous avons pu compléter notre information à la faveur d'un important terrassement effectué 
dans la carrière de Tourville-la-Rivière (Seine-Maritime), site majeur pour le Pléistocène moyen et supérieur de la vallée de la Seine. Ce site a livré à Gérard Carpentier, qui a assuré le suivi des travaux, de nombreux vestiges de faune et des artefacts lithiques qui avaient motivé la conduite de trois importantes campagnes de fouilles dirigées par Luc Vallin (SRA Nord-Pas-de-Calais) entre 1982 et 1984. Le principal horizon archéologique est estimé à environ 200000 ans, soit sub-contemporain du site de Ranville, récemment étudié.

Toujours pour les périodes anciennes, plusieurs opérations ont pu être menées dans des espaces géographiques diversifiés :

- à Barneville (Manche), un sondage a été pratiqué dans une paléoplage rapportable sur base altimétrique et chronostratigraphique au stade isotopique 9 (?). Cette plage a livré quelques artéfacts (galet aménagé en schiste, éclats et outils en silex). Ceux-ci constituent le plus ancien témoignage d'occupation de Basse-Normandie avec l'éclat de façonnage de biface collecté en sondage à Gatteville ;

- à Saint-Pierre-lès-Elbeuf (Seine-Maritime), le niveau archéologique fouillé durant l'été 2005 a fait l'objet d'une seconde campagne. Si aucune structure tangible n'a été mise au jour, de nombreux groupements de petits éléments et d'esquilles pourraient témoigner de postes de débitage, de façonnage et d'entretien des outils. La série lithique (en cours d'analyse) comprend plusieurs milliers de pièces lithiques où figurent des éléments de chaînes opératoires de débitage et de façonnage, et quelques outils dont des bifaces. Par ailleurs, le niveau archéologique a livré de rares pièces de faune mal conservées ;

- à Digulleville (Manche), des artefacts avaient été mis au jour par l'implantation de réseaux. Ces objets lithiques se rapportaient, fait exceptionnel, à l'Acheuléen. Les travaux envisagés par la commune (rectification d'un virage) ont motivé la conduite d'un sondage visant à préciser l'état sanitaire de ce site où s'était implantée une carrière de granite et de "tuf» (granite arénisé). Plusieurs niveaux d'occupations ont pu être reconnus. L'intérêt majeur de cette opération réside dans la grande diversité des roches locales, autres que le silex, mises en œuvre par les Paléolithiques (grès, granite, quartz, microgranite, diorite, dolérite). Toutes ces matières premières proviennent d'un environnement proche, le littoral de l'époque (utilisation de galets). Ces occupations pourraient se rapporter à l'avant-dernier interglaciaire et au début de l'avant-dernière glaciation (vers 200000 à 180000 ans ?).

Si les témoignages du Paléolithique inférieur s'avèrent peu nombreux en BasseNormandie, l'année 2007 apporte de nouveaux éléments sur les cultures des premiers peuplements. La découverte sur une ancienne terrasse de l'Orne à Biéville-Beuville (Calvados) de pièces bifaciales confectionnées sur masse centrale dans du silex et dans du grès illustre une nouvelle fois les périodes anciennes et surtout la mise en œuvre de grès allochtones. Des sondages devront être tentés afin de préciser le contexte chronostratigraphique de cette industrie.

Notre activité s'est aussi portée sur les peuplements du Paléolithique moyen, notamment avec l'examen des séries collectées à Rânes depuis les années 1970 (Collection ancienne, Orne), la reconnaissance d'un niveau moustérien à Portbail (Manche) et la fouille d'une occupation moustérienne à Saint-Pierre-Eglise.

Les mobiliers collectés à Rânes (Orne) présentent les mêmes caractéristiques que le matériel issu de la fouille du site de Saint-Brice. Si les modules s'avèrent plus importants, 
la série apparait constituée de bifaces, de pièces bifaciales partielles et de racloirs à retouche bifaciale.

L'érosion des rivières qui débouchent dans le havre de Portbail (Manche) met au jour diverses structures historiques, et fait plus rare, préhistoriques. C'est un niveau d'occupation du Paléolithique moyen qui a été ici mis en évidence. L'assemblage comporte, outre un biface, de nombreux produits de débitage où la méthode Levallois est attestée (Fig. ${ }^{\circ} 1$ : Débitage Levallois (commune : Porbail)). L'intérêt de cette découverte apparait multiple, du fait de la rareté des occupations paléolithiques dans le centre de la Manche et par la présence d'une pièce bifaciale.

Enfin, la découverte d'une grande pièce bifaciale pour le gisement de Saint-PierreÉglise - Clitourps avait suscité notre intérêt du fait de la rareté des "faciès " à outils bifaciaux dans le Cotentin et justifié une campagne de sondages visant à préciser la localisation d'un éventuel site de production. Par ailleurs, rappelons que le Cotentin « continental » n'a livré jusqu'alors que peu de vestiges, hormis quelques pièces trouvées hors contexte (Bricquebec, Auderville). Les sondages effectués à Saint-Pierre-Église en 2006 avaient révélé la conservation partielle de niveaux d'occupation rapportables au Paléolithique moyen.

La campagne de fouille conduite en 2007 a permis de mettre en évidence l'existence d'une nappe de vestiges correspondant à une implantation sur un sommet topographique, le mont Etolan. Si les niveaux superficiels ont été démantelés, les implantations dans les dépressions du substrat constitué d'un conglomérat du Trias ont été préservées.

Les observations conduites en 2007 confirment celles de 2006, à savoir un âge tardif pour ces industries (post-stade 5). Les apports principaux de la fouille consistent :

- en la mise en évidence, à l'intérieur des terres, d'un gisement à pièces bifaciales du Paléolithique moyen, « faciès » rarissime en Cotentin,

- dans la mise au jour d'une occupation rapportable au dernier Pléniglaciaire,

- et dans la mise en œuvre de matières premières locales autres que le silex (grès, quartz, conglomérat du substrat).

Par rapport aux objectifs que nous nous étions fixés, deux opérations n'ont pu être menées à bien en raison des conditions atmosphériques. Cependant, le bilan de l'année 2007 s'avère une nouvelle fois très positif avec la conduite de trois opérations de terrain menées parallèlement aux travaux de post-fouille et de publication.

Les objectifs pour 2008 seront aussi ambitieux que ceux de 2007. Parallèlement à la poursuite des études portant sur les sites fouillés dans le but de proposer une synthèse portant sur l'ensemble de la Normandie, nous envisageons d'achever la fouille du site de Saint-Pierre-Église - Clitourps (Manche), de procéder aux sondages sur le gisement de Rânes (Orne) et de tenter un décapage intégral du niveau d'occupation du Paléolithique final d'Ouilly-le-Tesson (Calvados).

CLIQUET Dominique pour l'ensemble des acteurs du PCR 


\section{ANNEXES}

Fig. $\mathrm{n}^{\circ} 1$ : Débitage Levallois (commune : Porbail)

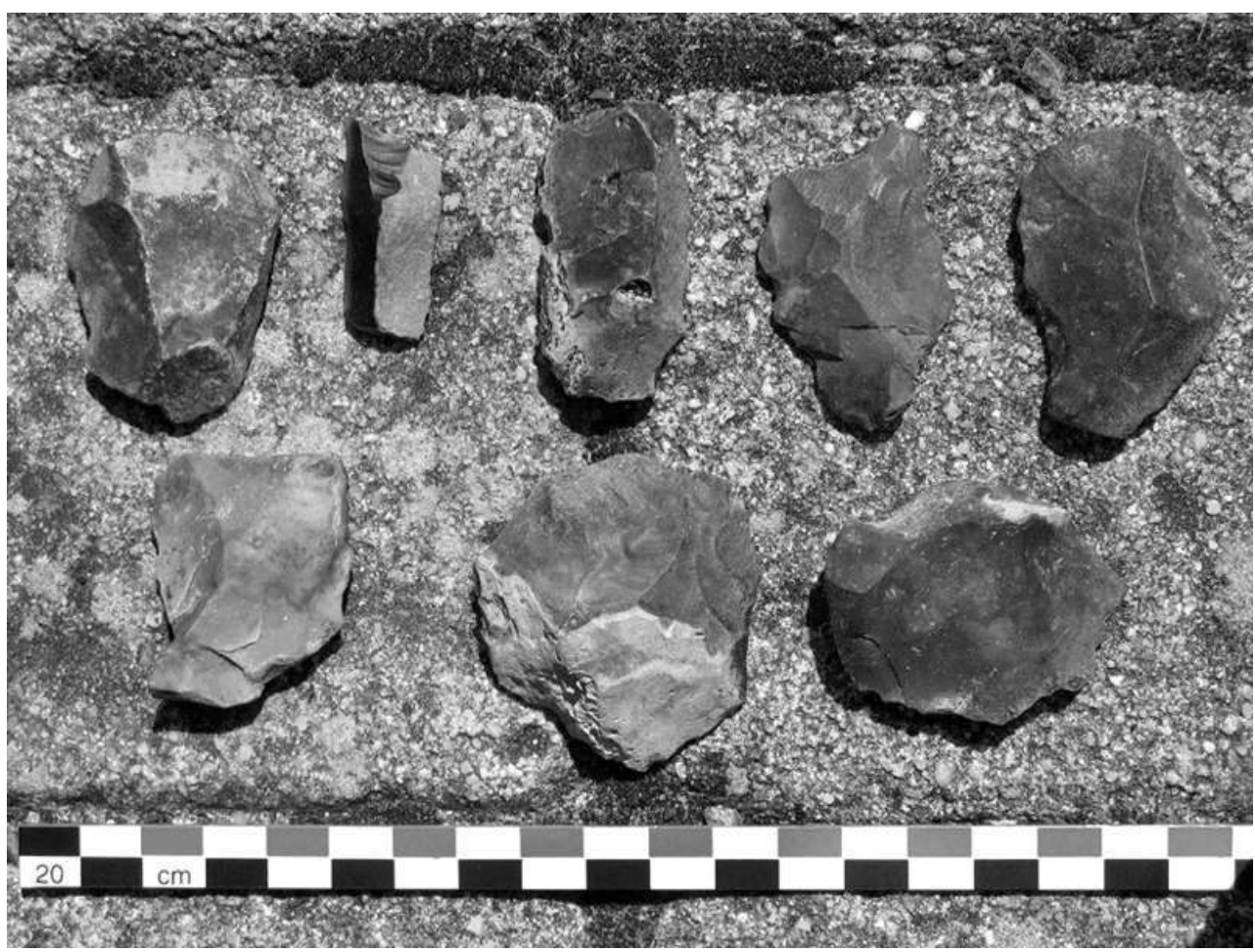

Auteur(s) : Cliquet, Dominique (SRA). Crédits : Cliquet, Dominique (2007)

INDEX

operation Projet collectif de recherche (PCR)

Index géographique : Basse-Normandie, Manche (50), Barneville-Carteret peuple Acheuléen, Moustérien

Index chronologique : Paléolithique

Thèmes : biface, boucherie, carrière, chronologie, débitage, éclat, faune, galet, granite, grès, Homo neanderthalensis, industrie lithique, littoral, matière première, mode de vie, occupation du sol, outil, racloir, silex

\section{AUTEURS}

\section{DOMINIQUE CLIQUET}

SRA 